\title{
A Case Report of Streptomycin Induced Cochlear Toxicity in Tuberculosis Patients
}

\author{
Ambika Nand Jha ${ }^{1}$, Akshay H Shah ${ }^{2}$, Upama N Trivedi ${ }^{3}$, Jignesh S. Patel ${ }^{4}$
}

\begin{abstract}
${ }^{1}$ Doctor of Pharmacy, Department of Pharmacy Practice, Indubhai Patel College of Pharmacy \& Research Centre, Dharmaj Anand, Gujarat, India; ${ }^{2}$ Associate Professor Department of Pharmacology, Indubhai Patel College of Pharmacy \& Research Centre, Dharmaj, Anand, Gujarat, India; ${ }^{3}$ Associate Professor, Department of Pharmacology, Indubhai Patel College of Pharmacy \& Research Centre, Dharmaj, Anand, Gujarat, India; ${ }^{4}$ Assistant Professor, Department of Pharmaceutics, Indubhai Patel College of Pharmacy \& Research Centre, Dharmaj, Anand, Gujarat, India
\end{abstract}

[Received: 10 September 2020; Accepted: 30 August 2020; Published: 1 December 2020]

\begin{abstract}
Streptomycin is a semi-synthetic, oldest aminoglycoside. It is the first line drug for tuberculosis. It may adversely produce ototoxicity, nephrotoxicity, neuromuscular blockage. The initial isolation of streptomycin from Streptomyces griseus. A 51 year old female visited to the medicine OPD in hospital. On presentation she complained of vomiting and vertigo from last few days. The patient recently diagnosed for Pulmonary TB by chest X-ray 3 month back. She taken streptomycin $0.75 \mathrm{mg}$ IV bid. As these were the new symptoms, the physician requested for otolaryngologist consultation to rule out the other causes and was insignificant. But the audiometry report showed hearing loss. The ototoxicity caused by aminoglycosides is permanent and can negatively affect the individual's quality of life. The early detection, management and therapeutic approaches for prevention of hearing loss is crucial. Reporting here is an interesting case of streptomycin induced cochlear toxicity. [Bangladesh Journal of Infectious Diseases, December 2020;7(2):99-101]
\end{abstract}

Keywords: Aminoglycoside; cochlear toxicity; vestibular toxicity; ototoxicity; tuberculosis

Correspondence: Ambika Nand Jha, Doctor of Pharmacy, Department of Pharmacy Practice, Indubhai Patel College Of Pharmacy \& Research Centre, Dharmaj Anand, Gujarat, India 388430; Email: nandjha99@ gmail.com; Cell no.: +918002787814, 7667422475 ;

Conflict of interest: The author has no conflicts of interest to declare.

Funding agency: This case study did not receive any specific grant from funding agencies in the public, commercial, or not-forprofit sectors.

Contribution to authors: Ambika Nand Jha Conception and Writing of case report. All authors read and approved the final manuscript.

How to cite this article: Jha AN, Shah AH, Trivedi UN, Patel JS. A Case Report of Streptomycin Induced Cochlear Toxicity in Tuberculosis Patients. Bangladesh J Infect Dis 2020;7(2):99-101

Copyright: (92020. Jha et al. Published by Bangladesh Journal of Infectious Diseases. This article is published under the Creative Commons CC BY-NC License (https://creativecommons.org/licenses/by-nc/4.0/). This license permits use, distribution and reproduction in any medium, provided the original work is properly cited, and is not used for commercial purposes.

\section{Introduction}

Aminoglycosides are often used as a part of treatment of life threatening illnesses such as septicaemia and tuberculosis (MDR-TB). Research has firmly established that aminoglycosides cause permanent hearing loss in humans ${ }^{1}$. Nephrotoxicity, ototoxicity and neuromuscular blockade are the 
most persistent and pertinent adverse reaction of aminoglycoside. Nephrotoxicity is reversible and clinically managed with hydration therapy, however ototoxicity is permanent and profoundly hinder the patient quality of life $e^{2-3}$. The Symptoms of cochlear damage consist of long-lasting hearing loss and or tinnitus, whereas disequilibrium dizziness, ataxia and/or nystagmus are common with vestibular damage $^{4-7}$. Aminoglycosides bind with iron, forming an oxidative compound that contributes to the formation of free radicals, which are involved in tissue damage in the body due to oxidative activities with proteins and other targets ${ }^{8}$. Reporting here is an interesting case of streptomycin induced cochlear toxicity.

\section{Case Presentation}

A 51 -year old female, from rural background visited to the medicine outpatient department of a hospital (Sharda Hospital). On presentation she complained of .fever, cough, which was sudden onset and persisted for last 5 Days along with burning micturition, abdomen pain four-five episode of Hematochezia, vomiting and vertigo from last few days. The patient recently diagnosed for Pulmonary TB by Chest X-Ray and Type-2 Diabetes 3 month back during a routine clinical check-up. Following were her blood reports:- FBS$220 \mathrm{mg} / \mathrm{dl}$. cholesterol: $258 \mathrm{mg} / \mathrm{dl}$. From last 3 months she take AKT-3 (R 450 mg, + E 800 mg + H $300 \mathrm{mg} 1$ Cap.), Streptomycin $0.75 \mathrm{~g}$ i.m twice daily for treatment of TB. And Metformin $500 \mathrm{mg}$ BD. On examination she was complaints of vertigo and vomiting. As these are the new symptoms the physician requested for ophthalmic consultation to rule out the other cause and was insignificant. But the audiometry report shows hearing loos. Patient's medical history and extensive literature review suggestive of suspected Streptomicin as the causal agent and discontinued. clarithromycin $500 \mathrm{mg}$ twice daily was started as alternative antibiotic choice for his TB. The patient was put on symptomatic therapy of injection thiamine, betahistine $10 \mathrm{mg}$ and cinnarazine $25 \mathrm{mg}$ OD, rabeparazole $20 \mathrm{mg}$ OD, B-Complex and Vitamin D Tab OD. The symptoms like vertigo, nystagmus were resolved slowly; however patients still complaints of minimal hearing loss.

\section{Discussion}

Streptomycin is used as first line therapy in pulmonary tuberculosis, and ototoxicity may occur after several weeks or months of its use, as in the present case. Hearing loss is irreversible most of the time, and audiometric monitoring is preponderant before, during and after therapy. A short literature review is carried out on the mechanisms of ototoxicity of these drugs, their prevention and monitoring. Aminoglycosides enter the inner ear fluids of the organ of Corti and the induce sensory hair cell death by different cellular mechanisms.

Mitochondrial protein production disruption, cellular membrane potentials changes, interaction with the transition metals, free radicals formation, c-Jun N-terminal kinase (JNK) activation, caspases and nucleases are few reasonable pathological mechanisms ${ }^{9}$. Aminoglycosides cause degeneration of sensory cells in the cochlea; usually involving the basal turn initially before progressing to the cochlea apex.

This is the basis for the initial high frequency hearing loss subsequently followed by hearing loss in the lower frequencies. Therefore in the early stages of aminoglycoside ototoxicity conversational hearing might not be affected ${ }^{10}$. While AGs preferentially target the bacterial ribosome, the inner ear and kidney are known to receive collateral damage in many patients receiving treatment ${ }^{11-12}$.

Hearing loss can be conductive or sensorineural and before hearing can be tested, the status of the auditory channel and tympanic membrane must be determined. This is performed with a combination of otoscopy and tympanometry. Otoscopy involves the visual inspection of the channel for signs of infection, wax, foreign bodies or other obstruction using an otoscope. It is also vital to assess the tympanic membrane for perforation or middle ear fluid collections and infections. Tympanometry should ideally be carried out to document middle ear function. In this procedure, a tympanometer probe is placed in the participant's auditory channel and the compliance of the tympanic membrane measured $^{13}$.

\section{Conclusion}

The adverse effects of ototoxocity can have awful consequences in person's quality of life. Therefore, early detection, management and therapeutic approaches for prevention of hearing loss is crucial. All the patients on chronic treatment with aminoglycosides should be monitored up to 6 months after cessation of aminoglycoside treatment.

Acknowledgements: We are very thankful to Dr. Akshay $\mathrm{H}$ Shah, Associate Professor Department of Pharmacology at Patel College of Pharmacy \& Research Centre, Dharmaj Anand, Gujarat for his help to complete this case. 


\section{References}

1. Cannizzaro E, Cannizzaro C, Plescia F, Exposure to ototoxic agents and hearing loss: a review of current knowledge. Hear Balan Commun. 2014;12(4):166-75

2. Petersen L, Rogers C. Aminoglycoside-induced hearing deficits-a review of cochlear ototoxicity. South African Family Practice. 2015;57(2):77-82

3. Jerome A, John AR, Wayne LG. Aminoglycoside-induced ototoxicity. CMAJ. 2015;187(1):E52

4. Jing Xi, Andra ET, Jochen S. New developments in aminoglycoside therapy and ototoxicity. Hear Res. 2011;281(12):28-37

5. Rogers C, Petersen L. A Aminoglycoside-induced balance de cits: a review of vestibulotoxicity. S Afr Fam Pract 2011;53(5);419-24

6. Charles AP, Shaun EB, Annette TN, Patricia MS, Marian C, Gwen AH, et al. Aminoglycoside Toxicity: Daily versus ThriceWeekly Dosing for Treatment of Mycobacterial Diseases. Clinical Infectious Diseases. 2004;38(11):1538-44

7. Mohammad R, Javadi B, Abtahi K, Gholami B, Safari M,
Payam T, et al. The Incidence of Amikacin Ototoxicity in Multidrug-Resistant Tuberculosis Patients. Iranian Journal of Pharmaceutical Research. 2011;10(4):905-11

8. Guthrie OW. Aminoglycoside induced ototoxicity. Toxicology. 2008;249(2-3):91-6

9. Huth ME, Ricci AJ, Cheng AG. Mechanisms of Aminoglycoside Ototoxicity and Targets of Hair Cell Protection. International Journal of Otolaryngology. 2011:1-9 10. Kisilevsky VE, Tomlinson RD, Ranalli PJ, Prepageran N. Monitoring vestibular ototoxicity. In: Roland PS, Rutka JA, editors. Ototoxicity. Hamilton: BC Decker; 2004:161-169

11. Hettig RA, Adcock JD. Studies on the toxicity of streptomycin for man: a preliminary report. Science 1946;103(2673):355-357

12. Hinshaw HC, Feldman WH, Pfuetze KH. Treatment of tuberculosis with streptomycin; a summary of observations on one hundred cases. Journal of the American Medical Association 1946;132(13):778-782

13. Moeller MP, Tomblin JB, Yoshinaga-Itano C, et al. Current state of knowledge: language and literacy of children with hearing impairment. Ear Hear 2007;28:740-53 